OPEN ACCESS

Edited by:

Di Jin,

Woods Hole Oceanographic Institution, United States

Reviewed by:

Christian T. K.-H. Stadtlander, Independent Researcher, St. Paul Minnesota, United States

Raúl Prellezo, AZTI-BRTA, Spain

*Correspondence: Iván Sola ivan.sola@ua.es

Specialty section This article was submitted to Marine Affairs and Policy, a section of the journal Frontiers in Marine Science

Received: 14 January 2020 Accepted: 22 May 2020 Published: 16 June 2020

Citation:

Sola I, Maynou F and Sánchez-Lizaso JL (2020) Bioeconomic Analysis of the EU Multiannual Management Plan for Demersal Fisheries in the Western Mediterranean. Spanish Fisheries as a Case Study. Front. Mar. Sci. 7:459. doi: 10.3389/fmars.2020.00459

\section{Bioeconomic Analysis of the EU Multiannual Management Plan for Demersal Fisheries in the Western Mediterranean. Spanish Fisheries as a Case Study}

\author{
Iván Sola ${ }^{1 *}$, Francesc Maynou ${ }^{2}$ and José Luis Sánchez-Lizaso' \\ 1 Department of Marine Science and Applied Biology, University of Alicante, San Vicente del Raspeig, Alicante, Spain, \\ ${ }^{2}$ Institut de Ciències del Mar, CSIC, Pg. Marítim de la Barceloneta, Barcelona, Spain
}

The Multiannual Management Plan embedded in Regulation EU 2019/1022 of the European Parliament and of the Council of June 20, 2019, envisages to reform Mediterranean demersal fisheries to restore stocks to maximum sustainability yields by 2025. This paper leverages a bioeconomic model based on a specific case study of the Western Mediterranean Sea to analyze the objectives of this new EU reform. We complement this analysis with simulations based on alternative management strategies: the reduction of fishing effort of 1-2 days-per-week and changes to selectivity patterns. Effects on artisanal fleets are also analyzed in order to assess scenarios that could achieve sustainability for all demersal fishing fleets. The results reveal that it is not possible to achieve the plan's aims for all stocks. Furthermore, the fishing time established is insufficient, although it would increase economic, and biological indicators for medium- and long-term periods. The best scenarios would be achieved by applying selective changes that provide for faster recovery of biological and economic indicators for trawler and artisanal fleets. The results also reveal that the reduction in the number of fishing days per week complemented with selectivity changes would have a lower socioeconomic impact than a reduction in fishing effort based entirely on fishing days or number of boats. In any case, Mediterranean demersal fisheries require a significant and well-planned reduction in fishing mortality levels over the next several years to recover and maintain sustainable exploitation.

Keywords: Mediterranean fisheries, multiannual management plan, bioeconomic modeling, Common Fisheries Policy, maximum sustainability levels

\section{INTRODUCTION}

The measures adopted by the European Union (EU) Common Fisheries Policy (CFP) for more than a decade (European Commission [EU], 2006, 2008, 2013) have proven inefficient for limiting the fishing mortalities required to achieve a sustainable exploitation levels of Mediterranean fishery stocks (Colloca et al., 2017). In 2015, the Mediterranean Sea and Black Sea (FAO Fishing Area 37) had the highest percentage of unsustainably fished stocks among the 16 major world statistical 
areas (Food and Agriculture Organization [FAO], 2018). Additionally, in the Malta Medfish4Ever Ministerial Declaration of March 30, 2017 , a 10-year work program was provided, proposing that $100 \%$ of the key Mediterranean fisheries should be managed with multiannual management plans to restore and maintain fish stocks at or below fishing mortality (F) levels capable of producing maximum sustainable yields (MSY). The results of the Mediterranean stock assessments of the Scientific Technical and Economic Committee of the European Commission (STECF) revealed that it was necessary to reduce the fishing mortality of Mediterranean stocks, particularly for demersal species presenting high levels of fishing mortality with respect to $F_{\text {MSY }}$ (Colloca et al., 2017; Libralato et al., 2018).

The new reform of the European CFP (EU Reg. 2013/1380) established the possibility of implementing science-based management plans and "multiannual plans" to ensure that fishing activities would remain environmentally, socially, and economically sustainable over the long term. The CFP also has the objective of ensuring the sustainability of the fishing sector, including artisanal and coastal fisheries that are undergoing important capacity reductions for structural reasons (e.g., low economic viability, lack of intergenerational replacement). The reformed CFP sets the stage for fishery managers and stakeholders to assume the responsibility of complementing and implementing plans for managing fisheries within their region.

A multiannual plan was implemented to help conserve the demersal stocks and to ensure sustainable operations within the Western Mediterranean Sea (West Med MAP, Regulation EU 2019/1022 of the European Parliament and of the Council of June 20; European Commission [EU], 2019), which extends along the northern Alboran Sea, the Gulf of Lions, and the Tyrrhenian Sea, covering the Balearic archipelago and the islands of Corsica and Sardinia, concerning France, Italy, and Spain. The plan included the regulation of blue and red shrimp (Aristeus antennatus), deep-water rose shrimp (Parapenaeus longirostris), giant red shrimp (Aristaeomorpha foliacea), European hake (Merluccius merluccius), Norway lobster (Nephrops norvegicus), and red mullet (Mullus barbatus). The plan aims to restore these stocks to MSY levels with the objective of ensuring social and economic viability of Mediterranean demersal fisheries. Fishing mortality that corresponds to MSY levels must be based on STECF (or other scientific bodies recognized by the EU or international level) stock assessments. Likewise, $\mathrm{F}_{\mathrm{MSY}}$ should be achieved progressively by 2020 wherever possible and by January 1, 2025, at the latest. They must then be kept within the mortality levels that produce MSY.

The new reform stated that fishing effort reduction should be supplemented with relevant technical or conservation measures

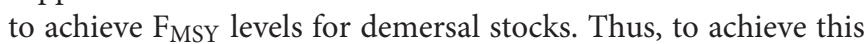
fishing mortality reduction and the $\mathrm{F}_{\mathrm{MSY}}$ levels, the measures adopted were to be combined with changes in fishery selectivity to restore fishery stocks, yields, and profits (Colloca et al., 2013; Libralato et al., 2018; Sola and Maynou, 2018b).

This paper aimed to assess the likelihood that the West Med MAP will achieve the CFP objectives, especially $\mathrm{F}_{\mathrm{MSY}}$

${ }^{1}$ http://www.fao.org/gfcm/meetings/medfish4ever/en/ levels for demersal stocks, via a quantitative bioeconomic model based on a specific case study in the Western Mediterranean Sea (GSA06). We use a bioeconomic model to assess the impacts of effort reduction and selectivity changes in demersal Mediterranean fisheries.

\section{MATERIALS AND METHODS}

\section{Demersal Fisheries of the Western Mediterranean Sea (GSA 06)}

The study area is GSA06 (Figure 1), a geographical region established by the General Fisheries Commission for the Mediterranean (GFCM), which manages data collection, monitoring, management, and assessment of Mediterranean fishery stocks ${ }^{2}$.

The GSA06 demersal fleets mainly comprise bottom trawlers (OTB), bottom longlines (HOK), and fixed or bottom net gears as gillnets or trammel nets included in the same fleet (GNS). The GNS fleet represents around $60 \%$ and the OTB fleet 35\% of the total demersal fleet as of 2015 in terms of the number of vessels (Table 1). However, the bottom trawlers represent the most productive gear in the Mediterranean fleet in terms of production (Lleonart and Maynou, 2003). Nevertheless, artisanal fisheries play significant roles in the socioeconomic and cultural heritage of coastal communities (Colloca et al., 2017).

The Mediterranean fishing fleet catches around 300 species, but only $10 \%$ are systematically represented in the market (Bellido et al., 2014), of which around 200 species are landed in GSA06. Of these, 25 species represent 83 and $80 \%$ of landings and economic value, respectively, in 2010 (Maynou, 2014). Among the Mediterranean fishing fleet, OTB represents the most diversified fisheries of all fleets (Lleonart and Maynou, 2003).

The management of Mediterranean demersal fisheries in the GSA 06, and other Mediterranean fisheries, is based on input measures that control fishing effort by limiting the capacity of the fleet (license scheme). Fishing activity is not permitted on weekends and the vessels are forced to return to base port with, a maximum of 12 fishing hours per day (Lleonart and Maynou, 2003; Bellido et al., 2020). There are minimum landing sizes for most target species exploited by demersal fleets, but they are not fully enforced, contributing to the low economic efficiency of fisheries exploitation (Colloca et al., 2013). OTB operate with gears with legal minimum mesh sizes in the codend of $40 \mathrm{~mm}$ (square mesh) or $50 \mathrm{~mm}$ (diamond mesh) (Sola and Maynou, 2018a). Also, artisanal fleets (HOK and GNS) operate with gears regulated (i.e., number of gears by vessel, mesh sizes of fixed nets, etc). Output management measures (i.e., Total Allowable Catch or Quotas) are not implemented in Mediterranean demersal fisheries (Smith and Garcia, 2014).

\section{Bioeconomic Model}

A bioeconomic model using data from GSA06 was developed to help analyze the West Med MAP's ability to achieve F $_{\text {MSY }}$ levels of demersal stocks. The model description is based on

${ }^{2}$ http://www.fao.org/gfcm/es/ 


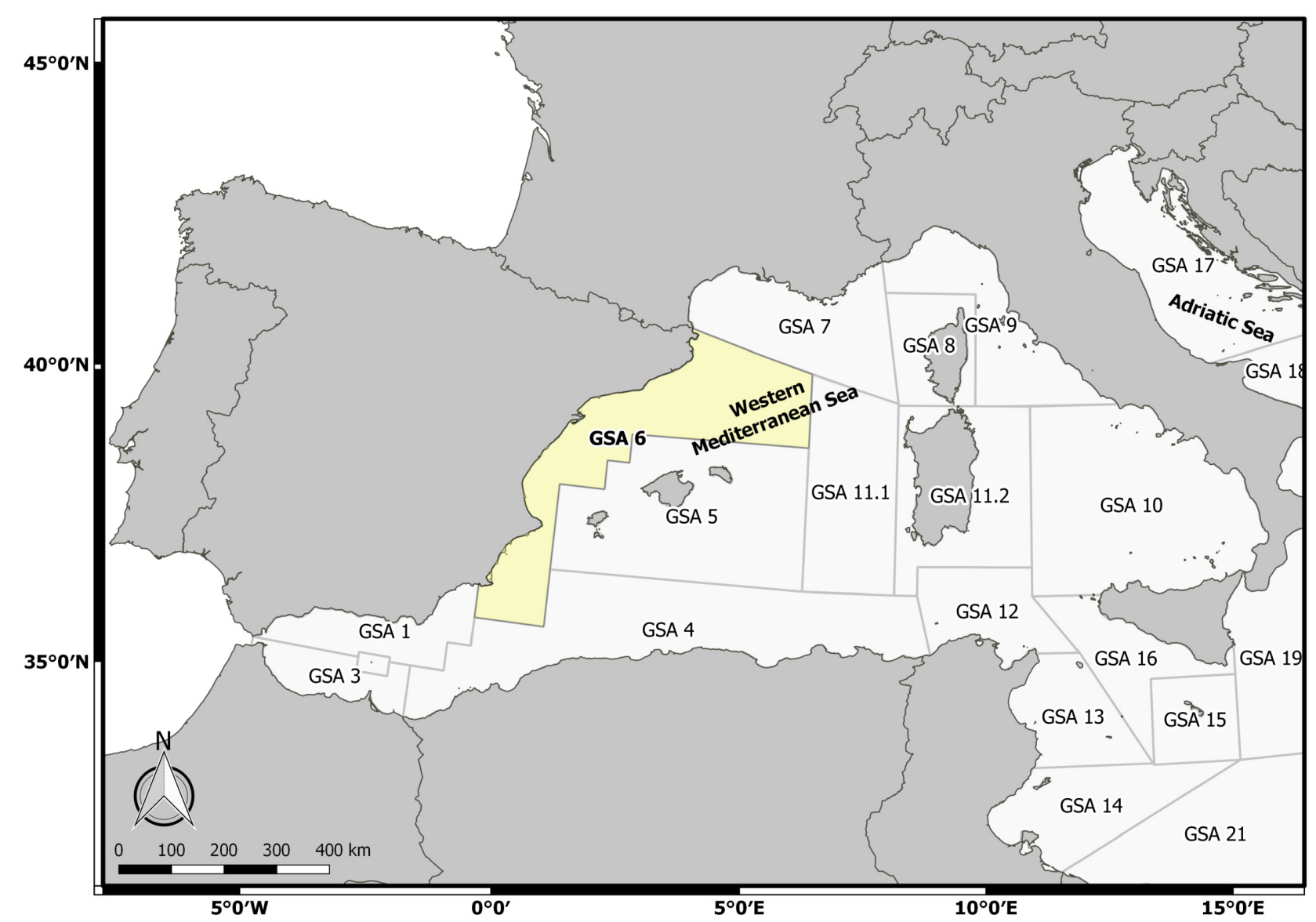

FIGURE 1 | GFCM division areas, including the GSA06 area of this study (coordinates obtained from http://www.fao.org/gfcm/en/).

TABLE 1 | Composition and fishing effort capacity of the Mediterranean demersal fisheries fleet of GSA06 in 2015 (from https://ec.europa.eu/fisheries/ cfp/fishing_rules/fishing_fleet_en).

\begin{tabular}{|c|c|c|c|c|}
\hline Demersal fleet & $\begin{array}{c}\text { Number of } \\
\text { vessels }\end{array}$ & $\begin{array}{c}\text { Average Declared } \\
\text { Power } \\
\text { (HP/vessel) }\end{array}$ & $\begin{array}{c}\text { Average Gross } \\
\text { Tonnage } \\
\text { (GT/vessel) }\end{array}$ & $\begin{array}{c}\text { Average days } \\
\text { at sea* } \\
\text { (day/vessel) }\end{array}$ \\
\hline Bottom trawl (OTB) & 485 & 196.1 & 59.9 & 215 \\
\hline Bottom longline (HOK) & 64 & 75.0 & 9.2 & 175 \\
\hline Fixed nets (GNS) & 833 & 39.8 & 4.9 & 170 \\
\hline
\end{tabular}

*Considering fisheries closures.

the research of Sola and Maynou (2018b), who developed a bioeconomic model to analyze the economic impact of $\mathrm{EU}$ Landing Obligation (European Commission [EU], 2013) and selectivity improvements based on results obtained using a modified trawler designed to reduce unwanted catches in the northern part of GSA06 (Sola and Maynou, 2018a). The novelty of our approach lies with its assessment of the interaction between trawler (OTB) and artisanal fleets (HOK and GNS) to analyze the objective of West Med MAP to achieve $\mathrm{F}_{\mathrm{MSY}}$ levels of stock assessments species on assessed by the STECF.

The Mediterranean subgroups of STECF and GFCM assess the fisheries stocks of each GSA via the data collection of the Data Collection Framework of the European Commission
(EU Reg. 665/2008: European Commission [EU], 2008). The most important GSA06 demersal species in economic terms, evaluated by stock assessments, are hake (M. merluccius), red mullet (M. barbatus), anglerfish (Lophius piscatorius), blue whiting (Micromesistius poutassou), red shrimp (A. antennatus), Norway lobster (N. norvegicus), and deep-water pink shrimp (P. longirostris) (Scientific Technical, and Economic Committee for Fisheries [STECF], 2013, 2014, 2015a,b, 2017). These species were used to develop the bioeconomic model of GSA06 demersal fisheries.

The bioeconomic model was developed using the Mediterranean Fisheries Simulation Tool (MEFISTO, Lleonart et al., 2003) that is a multispecies and multigear model. 
On the one hand, the biological submodel is based on an age-structured fish population dynamics model that include stock recruitment relationships, growth, natural mortality, maturity and length-weight relationships (Shepherd and Pope, 2002). On the other hand, the economic submodel is based on the economic units of fishing fleets as single firms. The revenues of the economic units derive from the sale of the main species described by the biological submodel, complemented by catches of other commercial species whose population dynamics are not explicitly modeled. Thus, the revenues of fishing fleets result from the catches of the main fisheries stocks and their commercial by-catch species, modeled as a proportion of main fisheries stocks (see Lleonart et al., 2003). The costs considered to obtain the net profits (relationship between revenues and costs) of fishing fleets are described in Sola and Maynou (2018b) and basically include common costs related to effort (primarily, energy costs), all other variable costs (such as vessel maintenance or engine repair, among others), fixed operating costs (such as fishing license, among others), depreciation cost and opportunity cost of capital. The biological model and the economic model are related via the fishing mortality that is proportional to the fishing effort. The fishing mortality obtained from fish stock assessments for each species and age was divided among each demersal fleet, proportionally to the catches. For more detailed information of MEFISTO model, see Lleonart et al. (2003), Maynou (2014), and Merino et al. (2015).

Mediterranean Fisheries Simulation Tool allows to study different economic metrics of fishing fleet, such as net profits by fleet, and the response of the stock under different management scenarios, like changes to fishing effort (reduction of fishing days, fleet reduction, ...) or technical measures (e.g., selectivity, catchability). It has been used in various studies of GSA06 (Lleonart et al., 2003; Maynou, 2014, 2019; Sola and Maynou, 2018b; Martín et al., 2019) and in other areas of the Mediterranean Sea (Merino et al., 2007; Silvestri and Maynou, 2009; Maravelias et al., 2014). MEFISTO is a free software that can be downloaded at http://mefisto2017.wordpress.com/.

The results of the stock assessments must remain robust to build an accurate bioeconomic model of Mediterranean fisheries (Maynou, 2014, 2019). Thus, the biological parameters obtained in the assessments and their results are used to parameterize the bioeconomic model using the most recent stock assessments of demersal species (Scientific Technical, and Economic Committee for Fisheries [STECF], 2013, 2014, 2015a,b, 2017). The economic parameters of the model were compiled using economic data from the Economic and Transversal data tables published by $\mathrm{STECF}^{3}$ complemented by surveys conducted in the MINOUW project $^{4}$. Furthermore, stock assessments were used to distribute fishing mortality results among the different fishing fleets according to catches per species (Scientific Technical, and Economic Committee for Fisheries [STECF], 2013, 2014, 2015a,b, 2017) (see text footnote 4).

\section{Simulation and Management Scenarios}

The management scenarios applied to the bioeconomic analysis are presented in Table $\mathbf{2}$ and are in line with the effort reduction required to reach the long-term $\mathrm{F}_{\mathrm{MSY}}$ for red mullet. This requires nearly a $73 \%$ reduction in the number of fishing days per year (215 to 56). We selected the $F_{M S Y}$ for red mullet (Figure 2), because it represents an intermediate situation between hake, the most overexploited species in the GSA06 area according to the available stock assessments, and red shrimp, the least overexploited species (Colloca et al., 2017). This scenario may be similar to the result of applying multispecies MSY (Quetglas et al., 2017).

Scenario 0 reflects no changes in fishing conditions and maintaining current levels of fishing mortality assuming an annual increase in catchability of $2 \%$ per year. Scenarios 1 and 2 imply an annual reduction of demersal fleet's effort of $20 \%$ (Scenario 1) and 10\% (Scenario 2) to achieve $\mathrm{F}_{\text {MSY }}$ levels without introducing changes in fishing patterns. Scenario 3 introduces a modified bottom-trawler design as discussed by Sola and Maynou (2018a) to reduce the catches of undersized M. merluccius and $M$. barbatus. This modification introduces the T90 mesh net of $50 \mathrm{~mm}$ mesh knotting $\left(90^{\circ}\right.$; Herrmann et al., 2013) replacing the current EU legal mesh sizes [diamond mesh of $50 \mathrm{~mm}$ knotting $\left(0^{\circ}\right)$ and square mesh of $40 \mathrm{~mm}$ knotting $\left.\left(45^{\circ}\right)\right]$ in the extension piece forward of the cod end in the trawl net. The T90 mesh net was also introduced in the codend to improve the selectivity

\footnotetext{
${ }^{3}$ https://stecf.jrc.ec.europa.eu/reports/economic

${ }^{4}$ The H2020 Research and Innovation Action "Science, Technology and Society Initiative to Minimize Unwatched Catches in European Fisheries” (2015-2019), contract no. 634495 .
}

TABLE 2 | Management scenarios considered in the bioeconomic model for demersal fisheries in GSA 06.

\begin{tabular}{|c|c|c|}
\hline Scenarios & Management scenario & $\begin{array}{c}\text { Total fishing } \\
\text { days } \\
\text { reduction (\% }\end{array}$ \\
\hline Scenario 0 & Business as usual, no management change. & 0 \\
\hline Scenario 1 & Annual reduction of $10 \%$ to reach $M$. barbatus $F_{M S Y}$ & 74 \\
\hline Scenario 2 & Annual reduction of $20 \%$ to reach $M$. barbatus $F_{M S Y}$ & 74 \\
\hline Scenario 3 & Change selectivity with T90 mesh net (see Sola and Maynou, 2018a) & 0 \\
\hline Scenario 4 & T90 mesh net $+10 \%$ annual effort reduction over 4 years & 34 \\
\hline Scenario 5 & T90 mesh net $+20 \%$ annual effort reduction over 4 years & 59 \\
\hline Scenario 6 & Reduction 2 days a week in 3 years & 40 \\
\hline Scenario 7 & Reduction 1 day per week in 3 years + T90 mesh net & 20 \\
\hline Scenario 8 & Reduction 2 days per week in 3 years + T90 mesh net & 40 \\
\hline
\end{tabular}




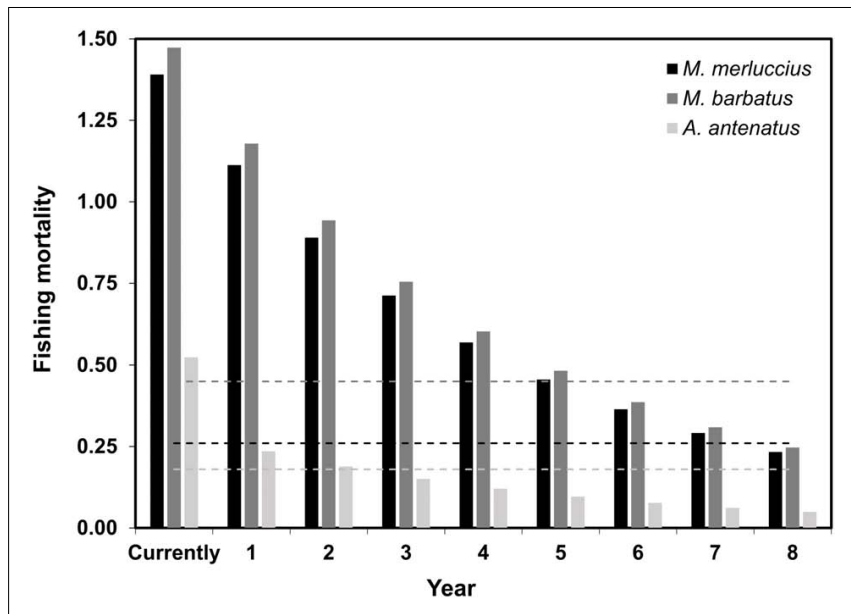

FIGURE 2 | Fishing mortality values with an effort reduction of 20\% per year for $A$. antennatus, M. barbatus, and $M$. merluccius. Dashed lines indicate the $\mathrm{F}_{\mathrm{MSY}}$ levels (M. merluccius, 0.26; M. barbatus, 0.45; $A$. antennatus, 0.18).

of A. antennatus by Deval et al. (2016). For other species no studies with T90 mesh net in Mediterranean demersal fisheries were found and no changes in selectivity pattern were modeled. Selectivity changes were modeled using the selectivity parameters $\mathrm{L}_{50}$ (length at $50 \%$ of the catch is retained) and SR (selection range) for $M$. merluccius (21.1 and $7.4 \mathrm{~cm} \mathrm{TL}$ ), M. barbatus (20 and $6.9 \mathrm{~cm} \mathrm{TL}$ ) and A. antennatus (23.3 and $8.4 \mathrm{~mm} \mathrm{CL}$ ). Scenarios 4 and 5 include a progressive annual reduction in the demersal fleet fishing effort with changes in the selectivity of bottom trawlers (viz., Scenario 3). Scenario 6 includes a $40 \%$ reduction in fishing effort over 3 years, which is equivalent to a 2-days-per-week reduction for demersal fleets. Finally, Scenarios 7 and 8 include a reduction of 1-2 days per week for demersal fleets and changes in selectivity of bottom trawling (viz., Scenario 3). All the management scenarios are introduced in 2020 based on West Med MAP (European Commission [EU], 2019).

The results of the stock assessments in Mediterranean fisheries are robust to parameterize a bioeconomic model for Mediterranean fisheries. Nevertheless, data from the spawning-stock biomass/recruitment (SSB/R) relationship are insufficient due to the short assessment period used to build medium term predictive models for Mediterranean fisheries (Maynou, 2019). Thus, recruitment was kept stochastic around a constant mean value over time as a result of the geometric mean of the most recent 3 years. This approach was applied to other bioeconomic models of the Mediterranean (Maravelias et al., 2014; Sola and Maynou, 2018b).

The given bioeconomic model was projected for the period 2015-2035 (2040 is an exception for Scenarios 0-2 for reaching $\mathrm{F}_{\mathrm{MSY}}$ ), assuming 2015 is the first year of the simulation according the most recent stock assessments. The uncertainty was treated assuming 1,000 iterations for each scenario analyzed in order to estimate the mean and 95\% confidence interval of the indicators analyzed. Table 3 presents the biological parameters used to develop a bioeconomic simulation. Tables 4, 5 present the economic parameters of the bioeconomic model.
The average prices in 2014 of target species $\left(\mathrm{p}_{i}\right)$ (Table 3) and commercial by-catch ( $\mathrm{p}_{s}$, estimated at $5.80 € \mathrm{~kg}^{-1}$ ) were estimated for the fleet from the price data series from the Fisheries Directorate of Catalonia and were assumed constant throughout the simulations. Finally, the net present value (NPV) of the management scenarios evaluated was estimated for net profits comparing gains and losses between management scenarios at different times, using a discount rate of $5 \%$.

\section{RESULTS}

\section{Reduction in Fishing Effort to Reach $\mathbf{F}_{\text {MSY Levels }}$}

Scenario 0 (status quo) shows the overexploited status of selected stocks where $\mathrm{F}>\mathrm{F}_{\mathrm{MSY}}$. A subsequent gradual increase in fishing mortality caused by the increase in catchability with decreases of SSB and catches of the main species is expected. Additionally, a gradual economic loss (i.e., profits and crew wages) for trawler and artisanal fleets is expected (Figures 3-5).

Management scenarios based on the gradual reduction in fishing effort needed to reach Mullus barbatus $\mathrm{F}_{\text {MSY }}$ (Scenarios 1 and 2) require an extended period of declining catches and economic loss lasting several years for trawlers (Figure 3), but not for artisanal fleets. These would see a one- to three-fold catch increase above the initial levels in the medium to long term. Scenario 1 (10\% reduction) shows a more progressive increase in the short-medium term for catches and a lower short term loss than Scenario 2 (20\% reduction) for trawler fleets.

Scenarios 1 and 2 would expect an increase in economic and catch terms for artisanal fleets (HOK and GNS) over the short term (Figures 4, 5). However, faster effort reductions (Scenario 2) exhibit a higher increase in catches and economic indicators (i.e., profits and crew wages) than slow effort reductions (Scenario 1).

Scenario 1 leads to a more progressive rebuilding of red mullet catches with a lower short term loss than Scenario 2. However, Scenario 2 shows a better recovery of SSB for red mullet and hake and, consequently, higher catches (Figure 6) in the medium to long terms (4\% vs. 14\% for hake and $-1.2 \%$ vs. $11 \%$ for red mullet in 2030 ); see Supplementary Tables S3, S5. Over the long term, both scenarios reduce fishing mortalities for the main species assessed, with a roughly $68 \%$ reduction for red mullet. For more detailed information, see Supplementary Tables S4, S6.

\section{Selectivity Change Introducing the T90 Mesh + Effort Reduction}

The modification of the selectivity pattern just with the T90 net (Scenario 3) or combined with effort reductions (Scenarios 4 and 5) would produce a short term loss for the trawler fleet during the first year compared with the status quo. However, in most scenarios, a rapid recovery of catches, and profits would be expected within a few years (Figure 7). More detailed information is presented in Supplementary Tables S7, S8. Nevertheless, our results indicate that, if effort reduction is too large (Scenario 5), the recovery will take longer, and 
TABLE 3 | Biological parameters used in the bioeconomic model of GSA 06. $F$ is the fishing mortality distributed among fishing fleets.

\begin{tabular}{|c|c|c|c|c|c|c|c|}
\hline Stock name & $\begin{array}{l}\text { Age } \\
\text { class }\end{array}$ & $\begin{array}{l}\text { Number } \\
\text { (000s) }\end{array}$ & $\begin{array}{c}\text { Maturity ogive } \\
\text { (Mat) }\end{array}$ & $\begin{array}{c}\text { Natural } \\
\text { mortality }(m)\end{array}$ & $F$ (OTB) & $F(\mathrm{HOK})$ & $F$ (GNS) \\
\hline M. merluccius & 0 & 100806 & 0.00 & 1.24 & 0.12 & 0.00 & 0.00 \\
\hline M. merluccius & 1 & 26126 & 0.15 & 0.58 & 1.22 & 0.00 & 0.00 \\
\hline M. merluccius & 2 & 2788 & 0.82 & 0.45 & 1.54 & 0.03 & 0.03 \\
\hline M. merluccius & 3 & 225 & 0.98 & 0.40 & 1.16 & 0.09 & 0.09 \\
\hline M. merluccius & 4 & 30 & 1.00 & 0.37 & 0.23 & 0.03 & 0.01 \\
\hline M. merluccius & 5 & 4 & 1.00 & 0.35 & 0.20 & 0.07 & 0.01 \\
\hline L. budegassa & 0 & 11817 & 0.09 & 1.08 & 0.01 & 0.00 & 0.00 \\
\hline L. budegassa & 1 & 4387 & 0.14 & 0.48 & 0.35 & 0.01 & 0.02 \\
\hline L. budegassa & 2 & 2481 & 0.21 & 0.37 & 1.52 & 0.03 & 0.08 \\
\hline L. budegassa & 3 & 295 & 0.30 & 0.32 & 1.25 & 0.03 & 0.07 \\
\hline L. budegassa & 4 & 50 & 0.41 & 0.29 & 0.27 & 0.01 & 0.01 \\
\hline L. budegassa & 5 & 24 & 0.54 & 0.27 & 1.23 & 0.03 & 0.07 \\
\hline L. budegassa & 6 & 10 & 0.66 & 0.26 & 6.56 & 0.14 & 0.35 \\
\hline L. budegassa & 7 & 0 & 0.91 & 0.25 & 2.73 & 0.06 & 0.15 \\
\hline L. budegassa & 8 & 0 & 1.00 & 0.24 & 2.73 & 0.06 & 0.15 \\
\hline P. longirostris & 0 & 109502 & 0.00 & 1.25 & 0.00 & 0.00 & 0.00 \\
\hline P. longirostris & 1 & 27656 & 0.13 & 0.82 & 0.11 & 0.00 & 0.00 \\
\hline P. longirostris & 2 & 11657 & 0.50 & 0.39 & 0.93 & 0.00 & 0.00 \\
\hline P. longirostris & 3 & 2779 & 0.79 & 0.28 & 1.52 & 0.00 & 0.00 \\
\hline P. longirostris & 4 & 396 & 0.90 & 0.24 & 2.01 & 0.00 & 0.00 \\
\hline P. longirostris & 5 & 44 & 0.97 & 0.22 & 1.49 & 0.00 & 0.00 \\
\hline P. longirostris & 6 & 3 & 1.00 & 0.21 & 1.49 & 0.00 & 0.00 \\
\hline M. barbatus & 0 & 93000 & 0.46 & 0.99 & 0.12 & 0.00 & 0.00 \\
\hline M. barbatus & 1 & 29100 & 0.76 & 0.46 & 2.13 & 0.00 & 0.10 \\
\hline M. barbatus & 2 & 2050 & 0.88 & 0.30 & 1.92 & 0.00 & 0.17 \\
\hline M. barbatus & 3 & 103 & 0.93 & 0.24 & 1.66 & 0.00 & 0.00 \\
\hline M. barbatus & 4 & 50 & 1.00 & 0.21 & 1.67 & 0.00 & 0.00 \\
\hline A. antennatus & 0 & 279420 & 0.08 & 1.25 & 0.00 & 0.00 & 0.00 \\
\hline A. antennatus & 1 & 72120 & 0.77 & 0.58 & 0.61 & 0.00 & 0.00 \\
\hline A. antennatus & 2 & 15798 & 1.00 & 0.44 & 0.27 & 0.00 & 0.00 \\
\hline A. antennatus & 3 & 2291 & 1.00 & 0.39 & 0.69 & 0.00 & 0.00 \\
\hline A. antennatus & 4 & 609 & 1.00 & 0.35 & 0.27 & 0.00 & 0.00 \\
\hline A. antennatus & 5 & 200 & 1.00 & 0.31 & 0.27 & 0.00 & 0.00 \\
\hline N. norvegicus & 1 & 34479 & 0.10 & 0.48 & 0.01 & 0.00 & 0.00 \\
\hline N. norvegicus & 2 & 31867 & 0.25 & 0.36 & 0.32 & 0.00 & 0.00 \\
\hline N. norvegicus & 3 & 16107 & 0.80 & 0.30 & 0.78 & 0.00 & 0.00 \\
\hline N. norvegicus & 4 & 4264 & 1.00 & 0.27 & 0.73 & 0.00 & 0.00 \\
\hline N. norvegicus & 5 & 1289 & 1.00 & 0.26 & 0.65 & 0.00 & 0.00 \\
\hline N. norvegicus & 6 & 448 & 1.00 & 0.24 & 0.48 & 0.00 & 0.00 \\
\hline N. norvegicus & 7 & 105 & 1.00 & 0.23 & 0.44 & 0.00 & 0.00 \\
\hline M. poutassou & 0 & 103067 & 0.00 & 1.18 & 0.02 & 0.00 & 0.00 \\
\hline M. poutassou & 1 & 34144 & 0.01 & 0.53 & 1.11 & 0.00 & 0.00 \\
\hline M. poutassou & 2 & 3709 & 0.61 & 0.39 & 2.38 & 0.00 & 0.00 \\
\hline M. poutassou & 3 & 253 & 1.00 & 0.34 & 1.51 & 0.00 & 0.00 \\
\hline M. poutassou & 4 & 25 & 1.00 & 0.31 & 1.97 & 0.00 & 0.00 \\
\hline M. poutassou & 5 & 3 & 1.00 & 0.29 & 1.97 & 0.00 & 0.00 \\
\hline
\end{tabular}

Data were obtained from the stock assessments (Scientific Technical, and Economic Committee for Fisheries [STECF], 2013, 2014, 2015a,b, 2017).

the long-term profits will be lower, although crew wages per day would increase.

Artisanal fleets would improve their catches and profits in all scenarios from the first year of the introduction until the implementation of management measures. The same is true for the demersal longline fleet (Figure 8), which increases their catches roughly by $64.7 \%$, and the gillnet fleet, which increases their catches by $66.3 \%$ during the medium term. For more detailed information, see Supplementary Tables S9, S11. The modification of trawl selectivity (Scenario 3) 
TABLE 4 | Economic parameters of the three fleets assessed for bioeconomic simulation of the GSA06.

\begin{tabular}{|c|c|c|c|c|c|c|}
\hline Fleet & $\begin{array}{c}\text { Initial effort } \\
\text { (Number days } \\
\text { by fleet * day) }\end{array}$ & $\begin{array}{c}\text { Share } \\
\text { coefficient }\end{array}$ & $\begin{array}{l}\text { Commercial } \\
\text { costs }\end{array}$ & $\begin{array}{l}\text { Energy costs } \\
\text { (€/fleet * day) }\end{array}$ & $\begin{array}{l}\text { Other variable } \\
\text { and fixed costs } \\
\text { (€/fleet * day) }\end{array}$ & $\begin{array}{c}\text { Capital value } \\
(000 \text { s } € / \text { fleet * day) }\end{array}$ \\
\hline Bottom trawl (OTB) & 104275 & 58 & 19 & 321167 & 14393.3 & 192637 \\
\hline Bottom longline ( $\mathrm{HOK}$ ) & 11200 & 38 & 19 & 8739 & 2889.0 & 9083 \\
\hline Fixed nets (GNS) & 141610 & 58 & 19 & 50227 & 11913.0 & 60799 \\
\hline
\end{tabular}

TABLE 5 | Average price of the main species assessed in GSA06, calculated from the 2000-2010 price data series from the Fisheries Directorate of Catalonia.

\begin{tabular}{|c|c|c|}
\hline Fleet (f) & Species & $\begin{array}{c}\text { Mean price } \\
(€ / \mathbf{k g}-1)\end{array}$ \\
\hline Bottom trawl (OTB) & Merluccius merluccius & 6.8 \\
\hline Bottom trawl (OTB) & Lophius budegassa & 7.8 \\
\hline Bottom trawl (OTB) & Parapenaeus longirostris & 9.9 \\
\hline Bottom trawl (OTB) & Mullus barbatus & 5 \\
\hline Bottom trawl (OTB) & Aristeus antennatus & 29.8 \\
\hline Bottom trawl (OTB) & Nephrops norvegicus & 19 \\
\hline Bottom trawl (OTB) & Micromesistius poutassou & 3.1 \\
\hline Longline (HOK) & Merluccius merluccius & 12.5 \\
\hline Longline (HOK) & Lophius budegassa & 9 \\
\hline Longline (HOK) & Parapenaeus longirostris & 0 \\
\hline Longline (HOK) & Mullus barbatus & 0 \\
\hline Longline (HOK) & Aristeus antennatus & 0 \\
\hline Longline (HOK) & Nephrops norvegicus & 0 \\
\hline Longline (HOK) & Micromesistius poutassou & 0 \\
\hline Fixed nets (GNS) & Merluccius merluccius & 8.1 \\
\hline Fixed nets (GNS) & Lophius budegassa & 9.1 \\
\hline Fixed nets (GNS) & Parapenaeus longirostris & 0 \\
\hline Fixed nets (GNS) & Mullus barbatus & 7.7 \\
\hline Fixed nets (GNS) & Aristeus antennatus & 0 \\
\hline Fixed nets (GNS) & Nephrops norvegicus & 0 \\
\hline Fixed nets (GNS) & Micromesistius poutassou & 0 \\
\hline
\end{tabular}

implies a direct benefit for the artisanal fleet, which will improve their catches, and profits without effort reductions (Supplementary Tables S10, S12).

According to our results, with the selectivity changes of Scenario 3, fishing mortality will decline by $54 \%$ more for red mullet than for hake ( $28 \%)$, but hake catches will increase by $36 \%$ more than red mullet (16\%) during the medium term (Figure 9 and Supplementary Tables S4, S6). The modification of selectivity will allow for a reduction in fishing mortality but will require effort reduction (Scenarios 4 and 5) and will allow attainment of red mullet $\mathrm{F}_{\mathrm{MSY}}$ levels. Under Scenario 4, catches for red mullet will increase over the medium term compared with Scenario 3, but a larger effort reduction (Scenario 5) will not yield the results enjoyed by the trawler fleet (Figure 7). Additionally, the three selectivity scenarios will significantly increase the SSB of the main species assessed (Figure 9).

\section{Reduction of Days Per Week}

The progressive reduction of 2 days per week in 3 years (Scenario 6) will produce a sustainable smaller short term loss but will significantly improve the biological and economic perspectives. Combining this strategy with an improvement in selectivity (Scenarios 7 and 8) on the trawl fleet will result in a higher loss during the short term but higher profits during the medium and long terms (Figure 10), which is estimated to be between 68 and $72 \%$. Additionally, the average daily wages could increase by 76 to $148 \%$, respectively.

For artisanal fleets, results will improve more when both selectivity improvements and effort reductions are applied to the trawler fleet (Scenarios 7 and 8) than when only the effort reduction is implemented (Figure 11).

In terms of biological parameters, scenarios having selectivity changes (Scenarios 7 and 8) result in larger SSBs, and catches of the main species during the mid-term (Figure 12) compared with the effort reduction without selectivity improvements (Scenario 6).

\section{DISCUSSION}

The previously published results of stock assessment point to an overexploited status of demersal fishery stocks $\left(\mathrm{F}>\mathrm{F}_{\mathrm{MSY}}\right)$ in all species assessed in the GSA06 region (Scientific Technical, and Economic Committee for Fisheries [STECF], 2013, 2014, 2015a,b, 2017). Our results reveal that the status quo scenario will not revert this situation, with other bioeconomic simulations for the Mediterranean demersal fisheries (Sola and Maynou, 2018b; Maynou, 2019), a significant reduction in fishing mortality is necessary. The West Med MAP goal suggests that the MSY level of the most vulnerable stock should be achieved by 2025 . However, this goal requires a drastic reduction in fishing mortality, such that its application in practice would be unrealistic (Maynou, 2014; Martín et al., 2019), because it will require an $80 \%$ reduction in fishing time. Moreover, the reduction in fishing time established in the West Med

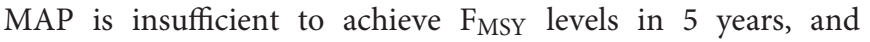
more time would clearly be necessary to reach MSY levels. However, our bioeconomic model results reveal that, with an effort reduction of $40 \%$ in the West Med MAP, catches of hake, and red mullet could increase. A faster approach to these reference points could be achieved if the reduction in fishing time were complemented with technical measures, such as selectivity improvements and temporary or permanent closures. In economic terms, the best results for demersal fleet according to our model (Table 6) would be achieved under scenarios that contemplate selectivity changes with or without effort reductions (Scenarios 3, 4, 7, and 8) because they provide the best economic indicators over the short term. However, 

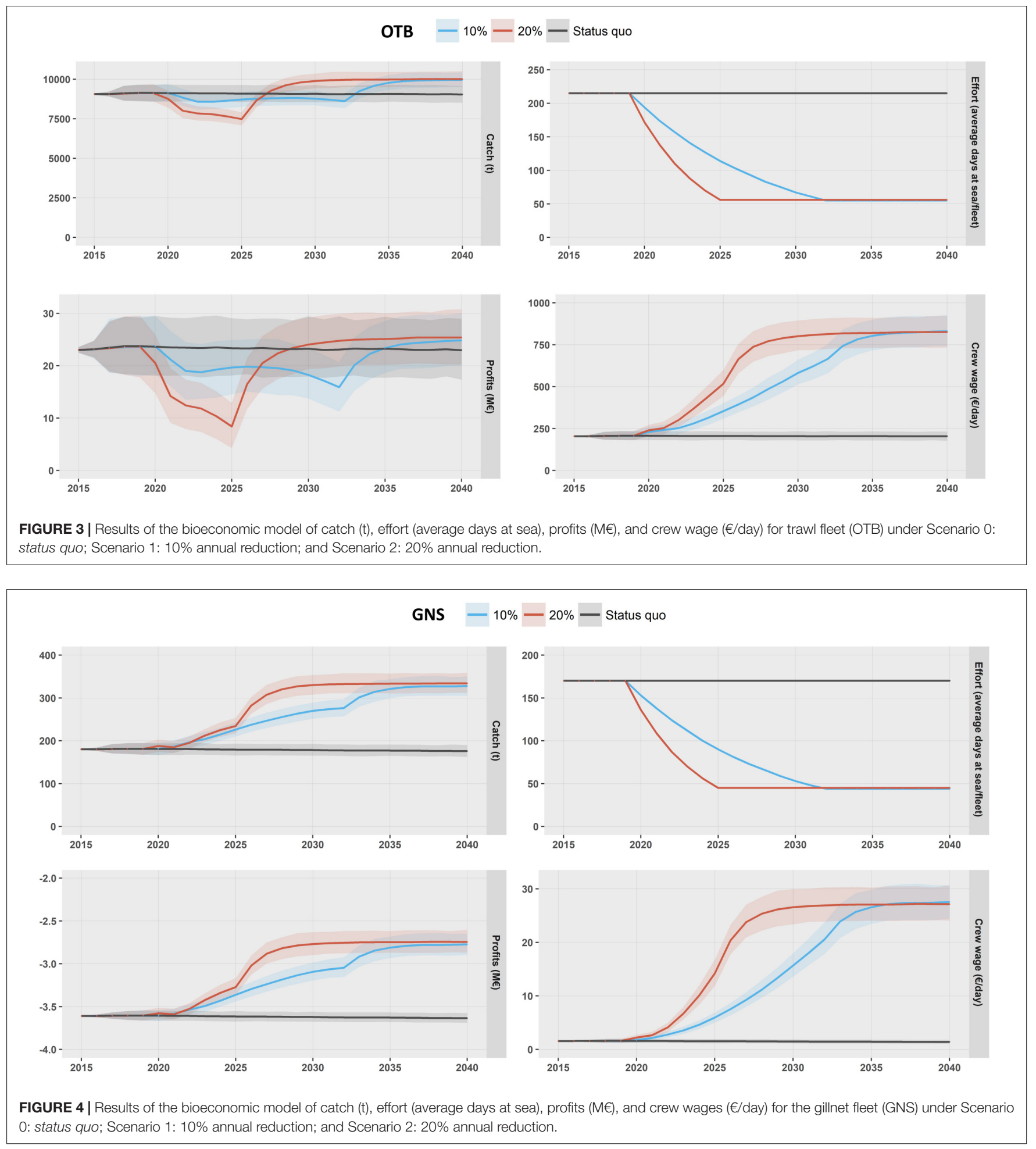

the best results for trawlers, according to our model, would be achieved under scenarios that contemplate selectivity changes with or without effort reductions (Scenarios 3, 7, and 8), because they provide a faster recovery of economic indicators over the short term and they produce higher profits and better working conditions for fishermen in the medium-long term. In the case of artisanal fisheries, the best results would be achieved under scenarios that contemplate selectivity changes with the higher effort reductions (Scenarios 4, 5, and 8) because they provide the higher profits and working conditions for fishermen with better crew wages and lower working days. In addition, both best results for trawlers and artisanal fisheries provide 

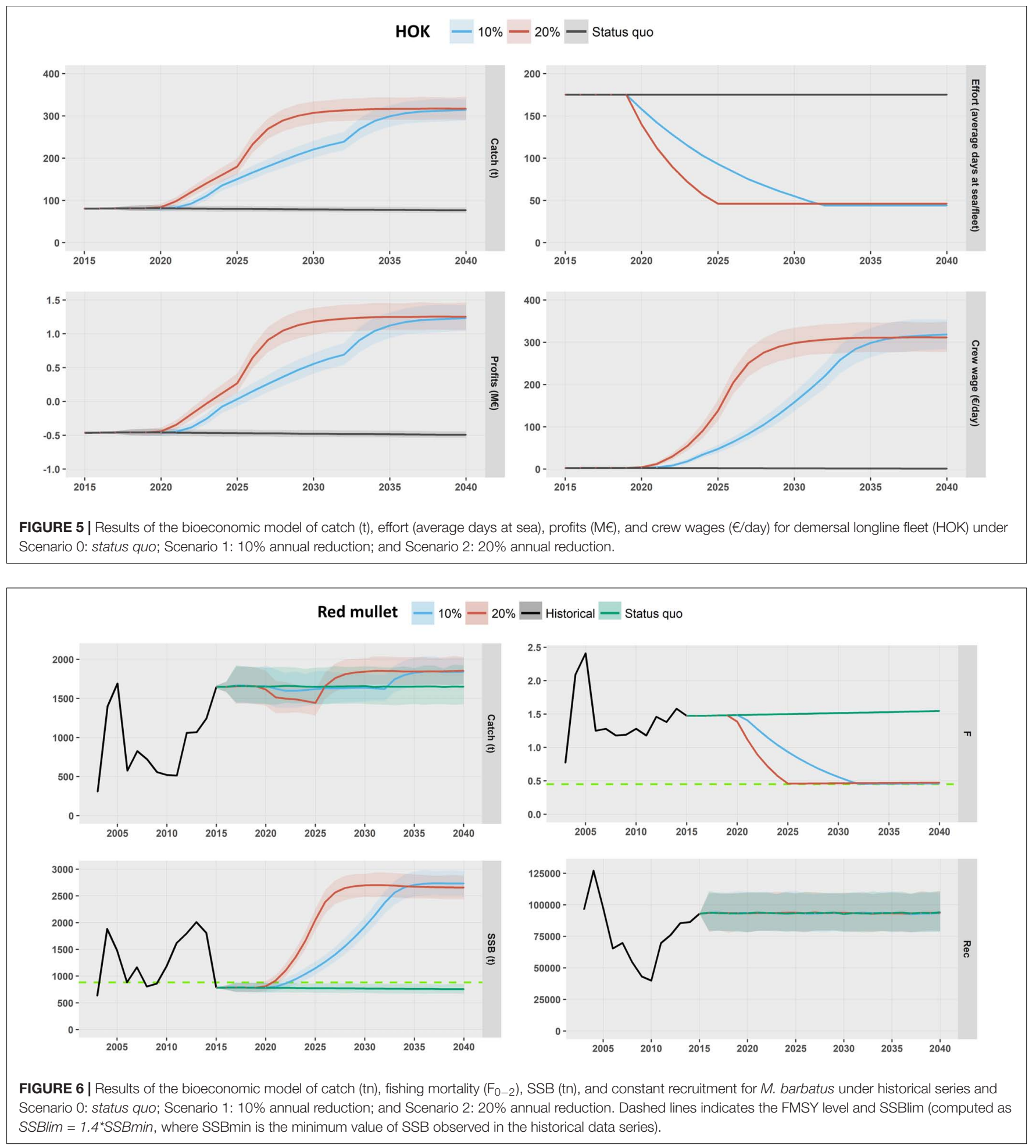

a fast recovery of biological indicators with high levels of SSB stocks. The management scenarios that include changes in the selectivity pattern for trawlers reduce fishing mortality more for red mullet than for hake, but the catches of hake increase faster than that of red mullet. This is caused by the fishing patterns of the trawler fleet, which inflicts a larger mortality on hake below the minimum conservation reference size than for red mullet (Sola and Maynou, 2018a). Changes in selectivity patterns have been recommended as more practical and efficient ways to recover Mediterranean stocks than mere effort reduction measures (Colloca et al., 2013; Maynou, 2014). Moreover, selectivity improvement would modify the reference 

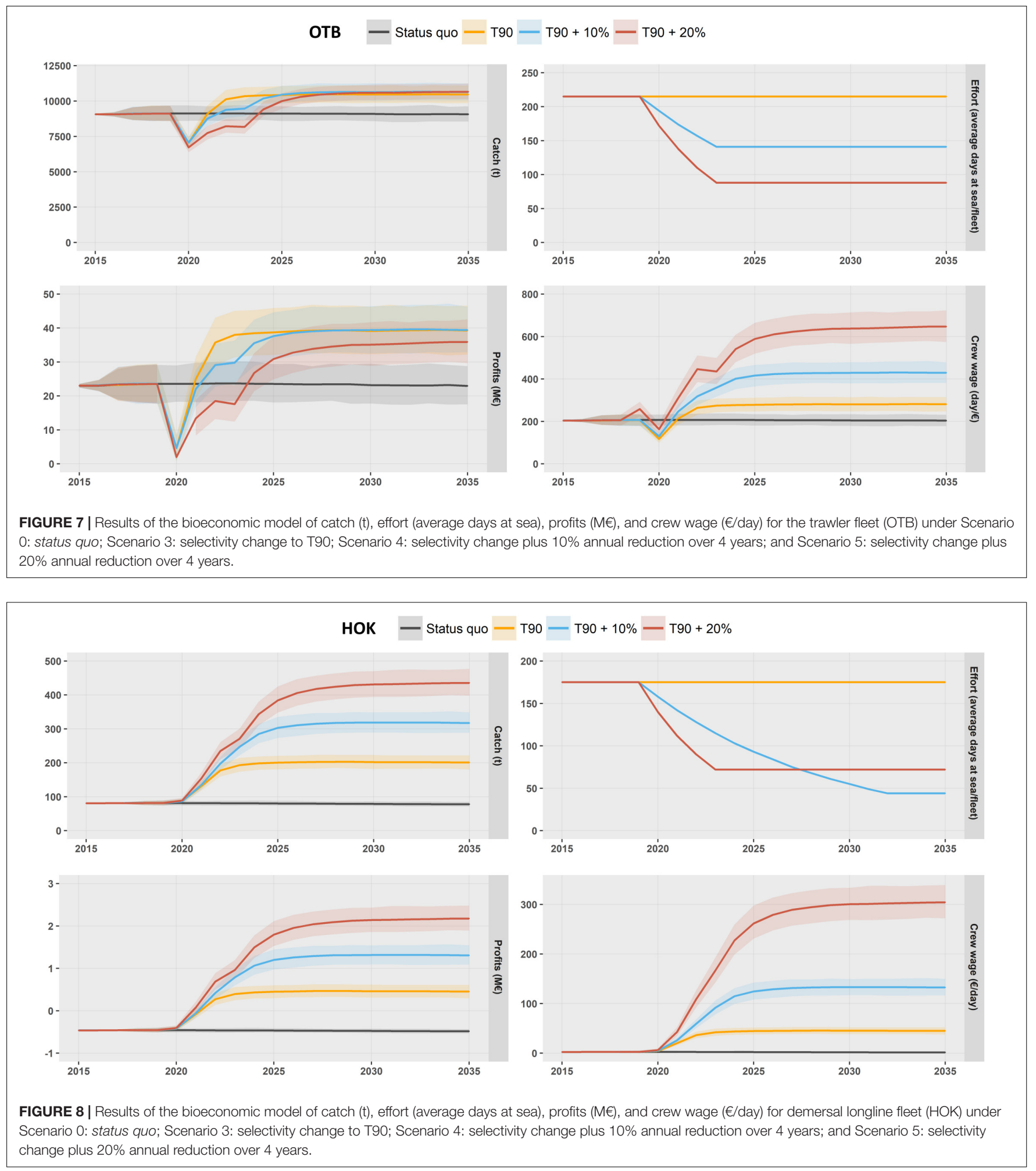

points while increasing $\mathrm{F}_{0.1}$ and approaching current target fishing mortalities (Sánchez Lizaso et al., 2020).

Any reduction in fishing mortality will produce a reduction in revenues over the short term with a marked increase over the long term. The reduction in fishing mortality is directly related to short term losses and higher long-term benefits for fishing fleets (Lleonart et al., 2003; Merino et al., 2015). The progressive reduction of $20-40 \%$ fishing days per year with a modification of selectivity for trawlers would result in small short term losses and higher profits for demersal fleets, resulting 

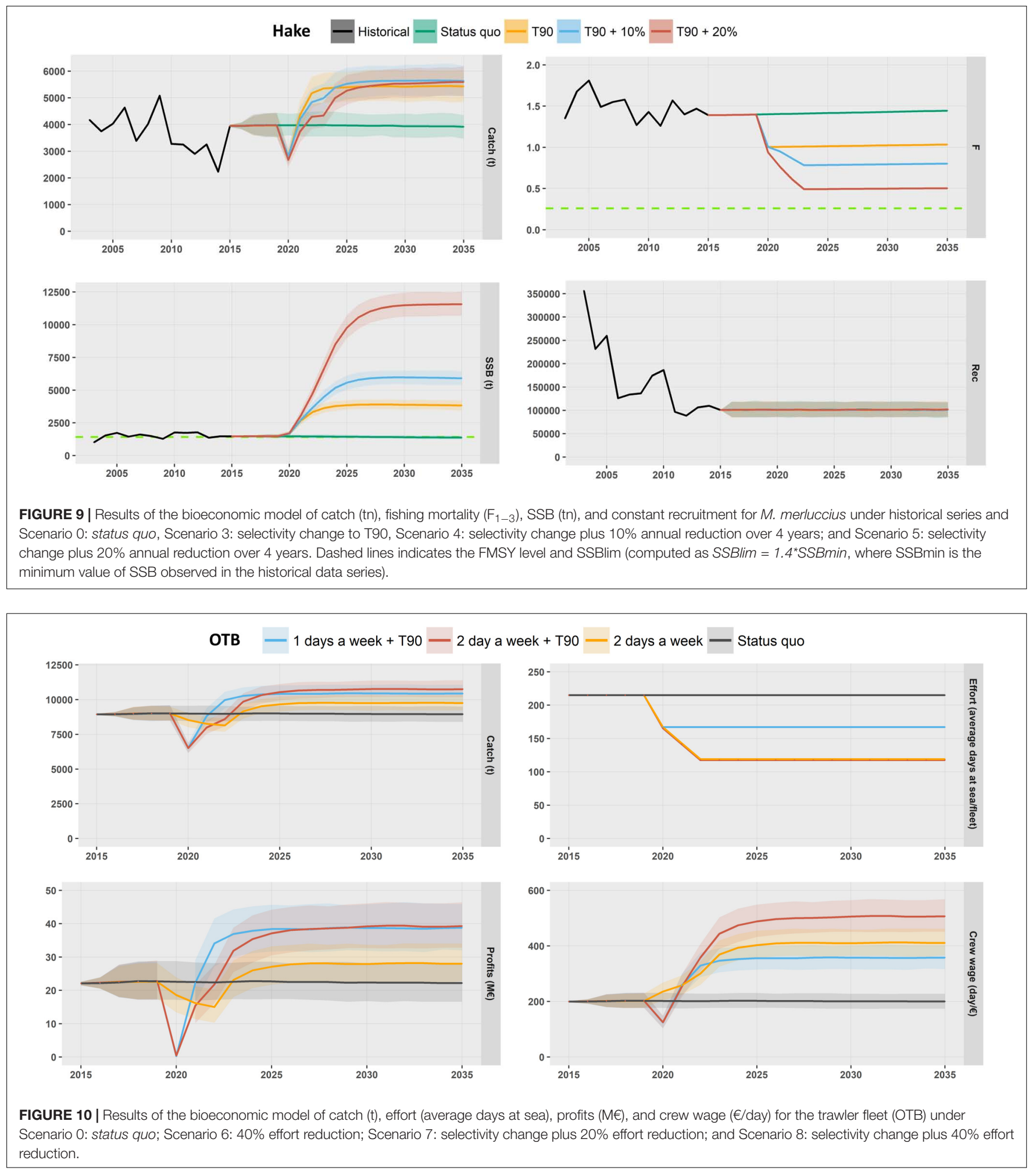

in lower short term losses compared with other scenarios. However, improving the selectivity pattern would contribute to the reduction in the juvenile mortality of commercial species (e.g., M. merluccius or M. barbatus) (Sala and Lucchetti, 2011; Sola and Maynou, 2018a) and overall improvements to the health productivity of marine ecosystems. It would also improve the reduction of discards as per the aim of reforms (European Commission [EU], 2013) for improving the stock status of target species and reducing the impact on Mediterranean ecosystems (Colloca et al., 2013; Maynou, 2014; Tsagarakis et al., 2014; 


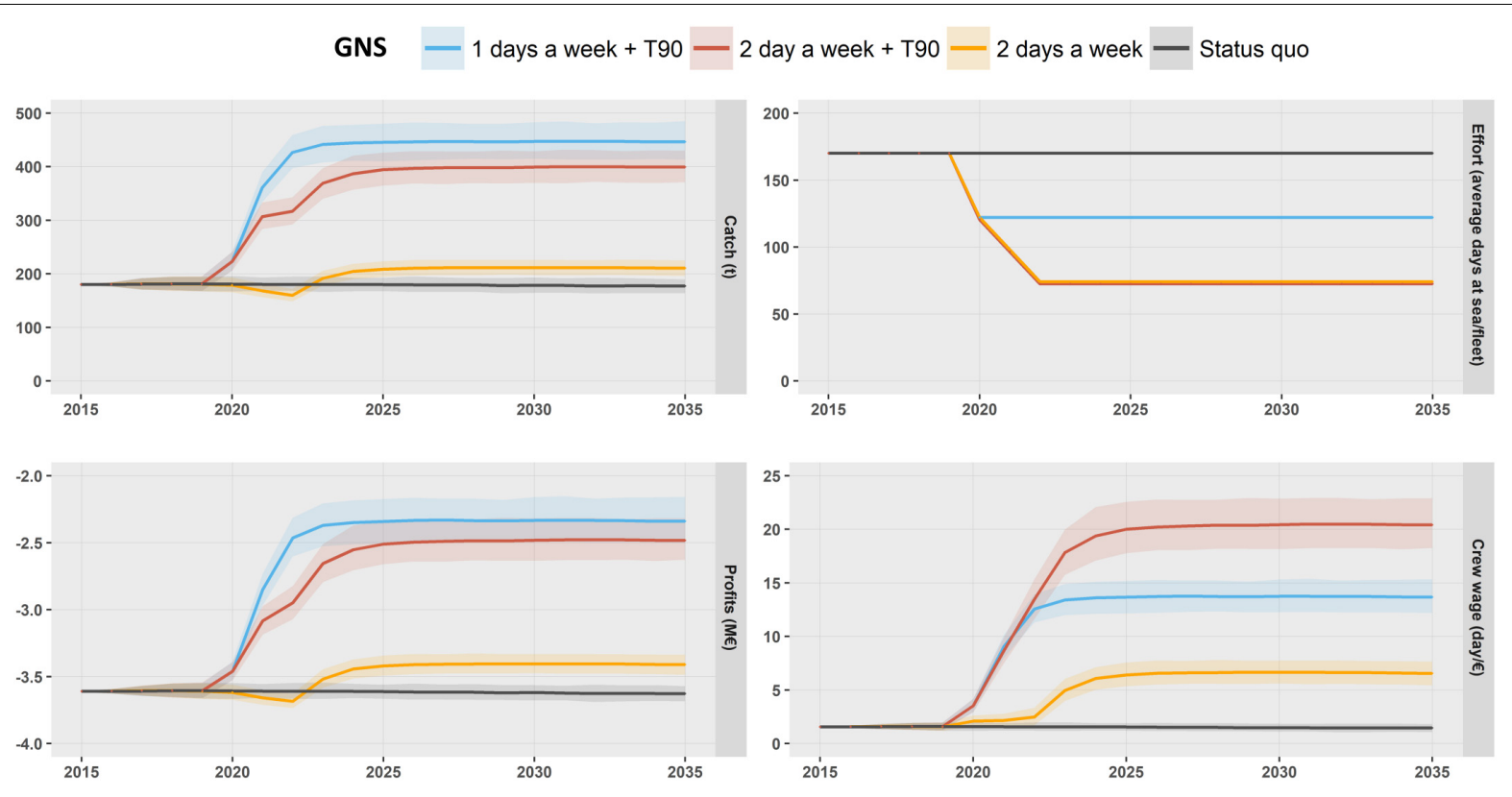

FIGURE 11 | Results of the bioeconomic model of catch (t), effort (average days at sea), profits (M€), and crew wage (€/day) for demersal gillnet fleet (GNS) under Scenario 0: status quo; Scenario 6: 40\% effort reduction; Scenario 7: selectivity change plus 20\% effort reduction; and Scenario 8: selectivity change plus 40\% effort reduction.

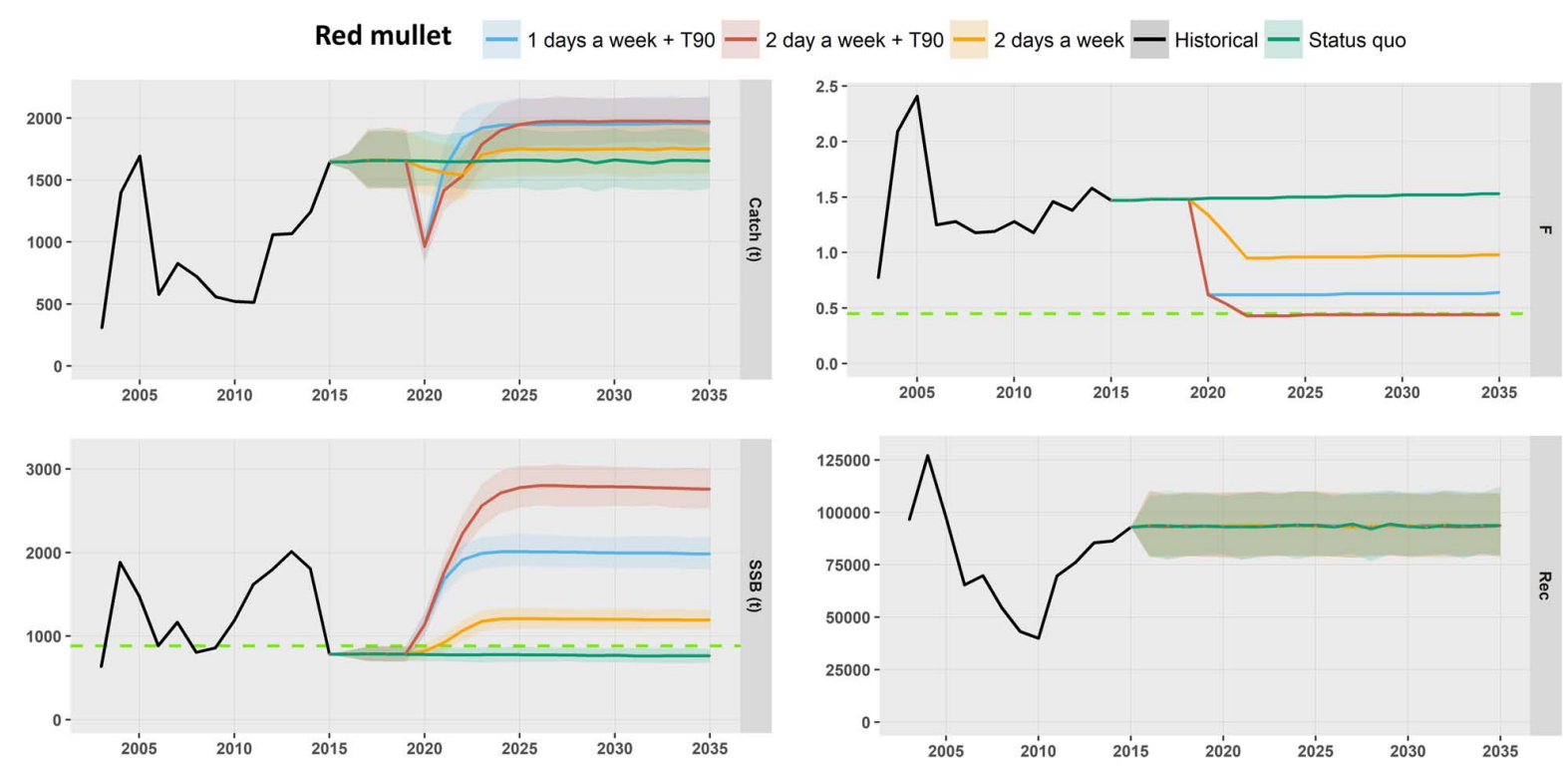

FIGURE 12 | Results of the bioeconomic model of catch (tn), fishing mortality $\left(\mathrm{F}_{1-3}\right)$, SSB (tn), and constant recruitment for $M$. barbatus under historical series and Scenario 0: status quo; Scenario 6: 40\% effort reduction; Scenario 7: selectivity change plus 20\% effort reduction; and Scenario 8: selectivity change plus $40 \%$ effort reduction. Dashed lines indicates the FMSY level and SSBlim (computed as SSBlim $=1.4^{*}$ SSBmin, where SSBmin is the minimum value of SSB observed in the historical data series).

Gullestad et al., 2015; Sardà et al., 2015; Prellezo et al., 2017). Moreover, improving selectivity would modify reference points and decrease the current levels of fishing mortality on $\mathrm{F}_{\mathrm{MSY}}$ (Scott and Sampson, 2011). Changes in selectivity and effort reductions could be complemented with permanent closures designed to protect a significant portion of extant marine habitats or local co-management plans to protect both juveniles and spawners (Maynou, 2014; Sánchez Lizaso et al., 2020).

It should be considered that technical measures having the same biological effect may have different socioeconomic impacts. In Mediterranean fisheries, it is important to consider not only the fishing time reductions but also the distributions of 
TABLE 6 | Average net present values (NVP) for net profits of demersal fleet according the introduction of the different management measures in 2020 (Scenarios 1-8).

\begin{tabular}{|c|c|c|c|c|c|c|c|c|c|}
\hline Year & $\begin{array}{c}\text { Scn. } 0 \\
\text { (Status quo) }\end{array}$ & $\begin{array}{l}\text { Scn. } 1 \\
(10 \%)\end{array}$ & $\begin{array}{l}\text { Scn. } 2 \\
(20 \%)\end{array}$ & $\begin{array}{c}\text { Scn. } 3 \\
\text { (T90) }\end{array}$ & $\begin{array}{c}\text { Scn. } 4 \\
(T 90+10 \%)\end{array}$ & $\begin{array}{c}\text { Scn. } 5 \\
(\text { T90 + 20\%) }\end{array}$ & $\begin{array}{c}\text { Scn. } 6 \\
\text { (2 days) }\end{array}$ & $\begin{array}{c}\text { Scn. } 7 \\
\text { (1 day + T90) }\end{array}$ & $\begin{array}{c}\text { Scn. } 8 \\
(2 \text { days }+ \text { T90) }\end{array}$ \\
\hline 2015 & 18.0 & 18.0 & 18.0 & 18.1 & 18.1 & 18.0 & 18.1 & 18.0 & 18.1 \\
\hline 2016 & 18.1 & 18.1 & 18.2 & 18.1 & 18.2 & 18.1 & 18.1 & 18.1 & 18.2 \\
\hline 2017 & 18.3 & 18.5 & 18.5 & 18.3 & 18.5 & 18.4 & 18.4 & 18.5 & 18.6 \\
\hline 2018 & 18.5 & 18.5 & 18.6 & 18.5 & 18.6 & 18.5 & 18.4 & 18.6 & 18.6 \\
\hline 2019 & 18.6 & 18.5 & 18.5 & 18.5 & 18.6 & 18.6 & 18.5 & 18.6 & 18.7 \\
\hline 2020 & 18.6 & 18.5 & 18.5 & 0.7 & 0.7 & -1.7 & 14.6 & -2.7 & -2.7 \\
\hline 2021 & 18.6 & 18.6 & 11.5 & 21.0 & 18.2 & 10.0 & 12.0 & 19.2 & 12.2 \\
\hline 2022 & 18.7 & 16.2 & 9.0 & 31.8 & 25.8 & 15.8 & 10.8 & 31.5 & 18.6 \\
\hline 2023 & 18.7 & 14.2 & 8.5 & 34.2 & 26.9 & 15.2 & 19.1 & 34.5 & 29.2 \\
\hline 2024 & 18.6 & 14.3 & 7.9 & 34.7 & 32.8 & 24.8 & 22.2 & 35.4 & 33.4 \\
\hline 2025 & 18.6 & 15.0 & 6.4 & 35.0 & 35.0 & 29.1 & 23.3 & 35.9 & 35.0 \\
\hline 2026 & 18.5 & 15.6 & 8.2 & 35.3 & 36.0 & 31.1 & 23.9 & 36.3 & 35.7 \\
\hline 2027 & 18.4 & 16.0 & 14.9 & 35.4 & 36.4 & 32.3 & 24.2 & 36.3 & 36.3 \\
\hline 2028 & 18.4 & 16.2 & 18.4 & 35.6 & 36.7 & 33.0 & 24.3 & 36.2 & 36.5 \\
\hline 2029 & 18.4 & 16.3 & 20.1 & 35.5 & 36.8 & 33.5 & 24.4 & 36.3 & 36.6 \\
\hline 2030 & 18.2 & 16.1 & 21.1 & 35.3 & 36.8 & 33.6 & 24.5 & 36.5 & 36.8 \\
\hline 2031 & 18.1 & 15.5 & 21.7 & 35.4 & 36.9 & 33.8 & 24.6 & 36.5 & 37.0 \\
\hline 2032 & 18.1 & 14.3 & 22.0 & 35.5 & 37.0 & 34.0 & 24.5 & 36.4 & 37.0 \\
\hline 2033 & 18.1 & 13.2 & 22.2 & 35.6 & 37.0 & 34.2 & 24.5 & 36.3 & 37.0 \\
\hline 2034 & 18.2 & 17.7 & 22.4 & 35.6 & 36.9 & 34.4 & 24.4 & 36.2 & 36.9 \\
\hline 2035 & 17.9 & 20.1 & 22.4 & 35.5 & 36.8 & 34.4 & 24.4 & 36.3 & 37.0 \\
\hline NPV & 294.0 & 349.6 & 347.2 & 603.7 & 598.6 & 519.1 & 437.3 & 609.2 & 584.7 \\
\hline
\end{tabular}

A discount rate of $5 \%$ has been used.

the reductions across the year to ensure that they do not affect market supplies (Sánchez Lizaso et al., 2020). In this model, the prices of the assessed species are assumed to be constant over time. Nevertheless, changes in trade can alter fish supplies and revenues for fishermen (Sánchez Lizaso et al., 2020). Concentrating the reduction during a single season can cause price decreases because of the irregular supply of fresh fish to the market (Samy-Kamal et al., 2015b). On the other hand, if effort reductions do not affect the continuous market supply (i.e., reducing 1-2 days per week; Scenarios $6-8)$, the reduction in the amount of catches over the short term would be balanced by an increase in the market price value because of the elasticity of supply and demand (Macher et al., 2008; Samy-Kamal et al., 2015a). During the medium to long term, the increase in the amount of catches will produce a higher supply to the market that may also affect prices if demand does not increase. However, the increase in average sizes of species (e.g., hake) must also be considered (Asche and Guillen, 2012).

A relevant aspect to consider is the distribution of fishing possibilities among vessels approved for the West Med MAP. The status quo scenario will produce a progressive reduction of the fleet but will allow the transfer of fishing times among boats, accelerating fleet reduction and the concentration of fishing rights to a fewer number of companies (Sánchez Lizaso et al., 2020). The highest amount of fresh fish in markets and harbors would be provided via trawlers that economically sustain fish markets and landing ports. In the absence of trawlers, artisanal fisheries could also disappear due to the unsustainability of landing, and marketing logistics rather than the gain of market opportunities.

Finally, the reductions of fishing effort would benefit artisanal fleets (GNS and HOK) more than trawlers in economic terms. These benefits would be significantly maximized when selectivity scenarios (Scenarios 4-5 and 7-8) were applied for trawler fleets since GNS and HOK target large hake while trawlers target smaller hake. Catches and profits for the artisanal fleet are directly related to effort reduction of the trawler fleet because of the negative effect of the trawler fleet on the artisanal fleet in gear competition for demersal stocks. In multispecies fisheries, as Mediterranean demersal fisheries, there is competition between fishing gears due to the dependence on the same pool of target species. Trawler fleets in Spanish Mediterranean area are clearly more dominant than artisanal fleets (GNS and HOK) because they produce a larger amount of species that are shared with the artisanal fleets. Therefore, reducing fishing effort for the trawl fleet directly benefits the artisanal fleet through competition for shared species, such as hake or red mullet (Lleonart et al., 2003, 2013; Merino et al., 2007). Thus, fishing effort reductions for trawlers would have higher benefits for artisanal fleets and would allow for their sustainability.

\section{CONCLUSION}

Management and regulation measures applied to date have not enabled the Mediterranean fisheries to move toward levels of sustainability (Colloca et al., 2017; Sánchez Lizaso et al., 2020). 
The current situation of Mediterranean stocks reflects the necessity to adopt proper management to recover sustainable exploitation levels of Mediterranean fisheries. This would protect ecosystems from indirect risks, such as global warming, while increasing the number of exotic species to the Mediterranean (Colloca et al., 2014; Corrales et al., 2018).

It is not possible to achieve the aim of West Med MAP to reach $\mathrm{F}_{\mathrm{MSY}}$ levels simultaneously for all stocks of Mediterranean demersal fisheries. It is, instead, necessary to find new reference points for introducing a multispecies approach that would not focus only on a single-species MSY. This approach should be combined with changes of selectivity patterns for trawling fishing to alter the carried out to date to produce the maximum levels for biological and economic indicators. In any case, it will be necessary to implement a significant and well-planned reductions to fishing mortality over the next few years to lead different stocks to meet $\mathrm{F}_{\mathrm{MSY}}$.

A reduction in fishing time will also be required to reduce current fishing mortalities to target stocks, but the socioeconomic impact of this reduction must also be considered. Different approaches to achieving the same reductions may have different socioeconomic impacts. The results of bioeconomic simulations reveal that the reduction of the number of fishing days per week with selectivity will have a lower socioeconomic impact than a reduction based only on fishing days or number of boats. It would also produce higher profits for demersal fleets.

\section{DATA AVAILABILITY STATEMENT}

All datasets generated for this study are included in the article/Supplementary Material.

\section{AUTHOR CONTRIBUTIONS}

IS and JS-L contributed to the conception and design of the study. IS and FM processed and analyzed the economic and

\section{REFERENCES}

Asche, F., and Guillen, J. (2012). The importance of fishing method, gear and origin: the Spanish hake market. Mar. Policy 36, 365-369. doi: 10.1016/j.marpol. 2011.07.005

Bellido, J. M., Carbonell Quetglas, A., García-Rodriguez, M., García-Jiménez, T., and González-Aguilar, M. (2014). The Obligation to Land All Catches Consequences for the Mediterranean. Brussels: EU.

Bellido, J. M., Sumaila, U. R., Sánchez-Lizaso, J. L., Palomares, M. L., and Pauly, D. (2020). Input versus output controls as instruments for fisheries management with a focus on Mediterranean fisheries. Mar. Policy 2020:103786. doi: 10.1016/ j.marpol.2019.103786

Colloca, F., Cardinale, M., Maynou, F., Giannoulaki, M., Scarcella, G., Jenko, K., et al. (2013). Rebuilding Mediterranean fisheries: a new paradigm for ecological sustainability. Fish Fish. 14, 89-109. doi: 10.1111/j.1467-2979.2011. 00453.x

Colloca, F., Mastrantonio, G., Lasinio, G. J., Ligas, A., and Sartor, P. (2014). Parapenaeus longirostris (Lucas, 1846) an early warning indicator species of global warming in the central Mediterranean Sea. J. Mar. Syst. 138, 29-39. doi: 10.1016/J.JMARSYS.2013.10.007 biological data to perform bioeconomic model. IS performed the bioeconomic analysis and wrote the first draft of the manuscript. IS, FM, and JS-L wrote sections of the manuscript. All authors contributed to manuscript revision, read, and approved the submitted version.

\section{FUNDING}

The authors declare that this study received funding from the European Parliament's Committee on Fisheries and was presented at the European Parliament in Brussels on November 23, 2018. This study received funding from the European Commission's Horizon 2020 Research and Innovation Program under Grant Agreement No. 634495 for the project, "Science, Technology, and Society Initiative to Minimize Unwanted Catches in European Fisheries" (MINOUW) and IS was grant funded by the University of Alicante and Sacyr Agua S.L. The funders were not involved in the study design, collection, analysis, interpretation of data, the writing of this article or the decision to submit it for publication.

\section{ACKNOWLEDGMENTS}

The authors thank the European Commission (DG MARE and the Joint Research Center) for facilitating access to the fisheries' Data Collection Framework database. We are grateful to the reviewers for their contributions, which have improved the quality of the manuscript.

\section{SUPPLEMENTARY MATERIAL}

The Supplementary Material for this article can be found online at: https://www.frontiersin.org/articles/10.3389/fmars. 2020.00459/full\#supplementary-material

Colloca, F., Scarcella, G., and Libralato, S. (2017). Recent trends and impacts of fisheries exploitation on mediterranean stocks and ecosystems. Front. Mar. Sci. 4:244. doi: 10.3389/fmars.2017.00244

Corrales, X., Coll, M., Ofir, E., Heymans, J. J., Steenbeek, J., Goren, M., et al. (2018). Future scenarios of marine resources and ecosystem conditions in the Eastern Mediterranean under the impacts of fishing, alien species and sea warming. Sci. Rep. 8, 1-16. doi: 10.1038/s41598-018-32666-x

Deval, M. C., Özgen, G., and Özbilgin, H. (2016). Selectivity of $50 \mathrm{~mm}$ T0 and T90 codends for commercial shrimp species in the Turkish deepwater trawl fishery, Eastern Mediterranean. J. Appl. Ichthyol. 32, 1041-1057. doi: 10.1111/jai.13128 European Commission [EU] (2006). European Council Regulation (EU) No 1967/2006 of 21 December 2006. Concerning Management Measures for the Sustainable Exploitation of Fishery Resources in the Mediterranean Sea, Amending Regulation (EEC) No 2847/93 and Repealing Regulation (EC) No 1626/94. Brussels: EU, 11-85.

European Commission [EU] (2008). Commission Regulation (EU) No 665/2008 of 14 July 2008 laying down detailed rules for the application of Council Regulation (EC) No 199/2008 concerning the establishment of a Community framework for the collection, management and use of data in the fisheries sector and support for scientific advice regarding the Common Fisheries Policy. Brussels: EU, 3-5. 
European Commission [EU] (2013). European Council Regulation No 1380/2013 of the European Parliament and of the Council of 11 December 2013 on the Common Fisheries Policy, amending Council Regulations EC No 1954/2003 and EC No 1224/2009 and repealing Council Regulations EC No 2371/2002 and EC No 639/2004 and Council Decision 2004/585/EC. Brussels: EU.

European Commission [EU] (2019). Commission Regulation (EU) No EU 2019/1022 of the European Parliament and of the Council of 20 June 2019 Establishing a Multiannual Plan for the Fisheries Exploiting Demersal Stocks in the Western Mediterranean Sea and amending Regulation (EU) No 508/2014. Brussels: EU, 1-15.

Food and Agriculture Organization [FAO] (2018). The State of World Fisheries and Aquaculture 2018 - Meeting the Sustainable Development Goals. Rome: FAO.

Gullestad, P., Blom, G., Bakke, G., and Bogstad, B. (2015). The 'Discard Ban Package': experiences in efforts to improve the exploitation patterns in Norwegian fisheries. Mar. Policy 54, 1-9. doi: 10.1016/j.marpol.2014.09.025

Herrmann, B., Wienbeck, H., Moderhak, W., Stepputtis, D., and Krag, L. A. (2013). The influence of twine thickness, twine number and netting orientation on codend selectivity. Fish. Res. 145, 22-36. doi: 10.1016/j.fishres.2013.03.002

Libralato, S., Colloca, F., Gücü, A. C., Maravelias, C. D., Solidoro, C., Villasante, S., et al. (2018). Editorial: challenges and opportunities for the EU common fisheries policy application in the mediterranean and black sea. Front. Mar. Sci. 5:299. doi: $10.3389 /$ fmars.2018.00299

Lleonart, J., and Maynou, F. (2003). Fish stock assessment in the mediterranean. Sci. Mar. 67, 37-49. doi: 10.3989/scimar.2003.67s137

Lleonart, J., Maynou, F., Recasens, L., and Franquesa, R. (2003). A bioeconomic model for Mediterranean fisheries, the hake off Catalonia (western Mediterranean) as a case study. Sci. Mar. 67, 337-351. doi: 10.3989/scimar.2003.67s1337

Lleonart, J., Maynou, F., and Salat, J. (2013). An analysis of fishing gear competition. Catalan fisheries as case studies. Sci. Mar. 77, 81-93. doi: 10.3989/ scimar.03691.04A

Macher, C., Guyader, O., Talidec, C., and Bertignac, M. (2008). A cost-benefit analysis of improving trawl selectivity in the case of discards: the Nephrops norvegicus fishery in the Bay of Biscay. Fish. Res. 92, 76-89. doi: 10.1016/j. fishres.2007.12.021

Maravelias, C. D., Pantazi, M., and Maynou, F. (2014). Fisheries management scenarios: trade-offs between economic and biological objectives. Fish. Manag. Ecol. 21, 186-195. doi: 10.1111/fme.12060

Martín, P., Maynou, F., Garriga-panisello, M., Ramírez, J., and Recasens, L. (2019). Fishing effort alternatives for the management of demersal fisheries in the western Mediterranean. Sci. Mar. 83, 293-304.

Maynou, F. (2014). Coviability analysis of Western Mediterranean fisheries under MSY scenarios for 2020. ICES J. Mar. Sci. 71, 1563-1571. doi: 10.1093/icesjms/ fsu061

Maynou, F. (2019). Co-viability of a Mediterranean demersal fishery affected by the discard ban under alternative management scenarios. Fish. Manag. Ecol. 26, 345-353. doi: 10.1111/fme.12365

Merino, G., Karlou-Riga, C., Anastopoulou, I., Maynou, F., and Lleonart, J. (2007). Bioeconomic simulation analysis of hake and red mullet fisheries in the Gulf of Saronikos (Greece). Sci. Mar. 71, 525-535. doi: 10.3989/scimar.2007.71n3525

Merino, G., Quetglas, A., Maynou, F., Garau, A., Arrizabalaga, H., Murua, H., et al. (2015). Improving the performance of a Mediterranean demersal fishery toward economic objectives beyond MSY. Fish. Res. 161, 131-144. doi: 10.1016/j.fishres. 2014.06.010

Prellezo, R., Carmona, I., García, D., Arregi, L., Ruiz, J., and Onandia, I. (2017). Bioeconomic assessment of a change in fishing gear selectivity: the case of a single-species fleet affected by the landing obligation. Sci. Mar. 81, 371-380. doi: 10.3989/scimar.04597.18A

Quetglas, A., Merino, G., González, J., Ordines, F., Garau, A., Grau, A. M., et al. (2017). Harvest strategies for an ecosystem approach to fisheries management in western Mediterranean demersal fisheries. Front. Mar. Sci. 4:106. doi: 10 3389/fmars.2017.00106

Sala, A., and Lucchetti, A. (2011). Effect of mesh size and codend circumference on selectivity in the Mediterranean demersal trawl fisheries. Fish. Res. 110, 252-258. doi: 10.1016/j.fishres.2011.04.012
Samy-Kamal, M., Forcada, A., and Sánchez Lizaso, J. L. (2015a). Daily variation of fishing effort and ex-vessel prices in a western Mediterranean multi-species fishery: implications for sustainable management. Mar. Policy 61, 187-195. doi: 10.1016/J.MARPOL.2015.08.015

Samy-Kamal, M., Forcada, A., and Sánchez Lizaso, J. L. (2015b). Effects of seasonal closures in a multi-specific fishery. Fish. Res. 172, 303-317. doi: 10.1016/J. FISHRES.2015.07.027

Sánchez Lizaso, J. L., Sola, I., Guijarro-García, E., Bellido, J. M., and Franquesa, R. (2020). A new management framework for western Mediterranean demersal fisheries. Mar. Policy 112:103772. doi: 10.1016/J.MARPOL.2019. 103772

Sardà, F., Coll, M., Heymans, J. J., and Stergiou, K. I. (2015). Overlooked impacts and challenges of the new European discard ban. Fish 16, 175-180. doi: 10.1111/ faf. 12060

Scientific Technical, and Economic Committee for Fisheries [STECF] (2013). Assessment of Mediterranean Sea stocks part I (STECF 13-22). EUR 26329 EN, JRC 86087. Brussels: Publications Office of the European Union.

Scientific Technical, and Economic Committee for Fisheries [STECF] (2014). Assessment of Mediterranean Sea stocks-part 1 (STECF-14-17). EUR 26955 EN, JRC 93120. Brussels: Publications Office of the European Union.

Scientific Technical, and Economic Committee for Fisheries [STECF] (2015a). Mediterranean Assessments Part 1 (STECF-15-18). EUR 27638 EN, JRC 98676. Brussels: Publications Office of the European Union.

Scientific Technical, and Economic Committee for Fisheries [STECF] (2015b). Mediterranean Assessments Part 2 (STECF-15-06). EUR 27221 EN, JRC 95822. Brussels: Publications Office of the European Union.

Scientific Technical, and Economic Committee for Fisheries [STECF] (2017). Mediterranean Assessments 2016- part 2 (STECF-17-06). EUR 28359 EN. Brussels: Publications Office of the European Union.

Scott, R. D., and Sampson, D. B. (2011). The sensitivity of long-term yield targets to changes in fishery age-selectivity. Mar. Policy 35, 79-84. doi: 10.1016/J. MARPOL.2010.08.005

Shepherd, J. G., and Pope, J. G. (2002). "Dynamic pool models II: short- term and long-term forecasts of catch and biomass," in Handbook of Fish Biology and Fisheries, Vol. 2, eds P. J. B. Hart and J. D. Reynolds (Malden, MA: Blackwell Publishing), 164-188.

Silvestri, S., and Maynou, F. (2009). Application of a bioeconomic model for supporting the management process of the small pelagic fishery in the Veneto Region, northern Adriatic Sea, Italy. Sci. Mar. 73, 563-572. doi: 10.3989/scimar. 2009.73 n 3563

Smith, A. D. M., and Garcia, S. M. (2014). Fishery management: contrasts in the mediterranean and the Atlantic. Curr. Biol. 24, R810-R812. doi: 10.1016/J.CUB. 2014.07.031

Sola, I., and Maynou, F. (2018a). Assessment of the relative catch performance of hake, red mullet and striped red mullet in a modified trawl extension with T90 netting. Sci. Mar. 82, 19-26. doi: 10.3989/scimar.04711.04A

Sola, I., and Maynou, F. (2018b). Bioeconomic analysis of the effects of modifying the trawl extension piece with T90 netting. Sci. Mar. 82, 27-37. doi: 10.3989/ scimar.04715.06A

Tsagarakis, K., Palialexis, A., and Vassilopoulou, V. (2014). Mediterranean fishery discards: review of the existing knowledge. ICES J. Mar. Sci. 71, 1219-1234. doi: 10.1093/icesjms/fst074

Conflict of Interest: The authors declare that the research was conducted in the absence of any commercial or financial relationships that could be construed as a potential conflict of interest.

Copyright (c) 2020 Sola, Maynou and Sánchez-Lizaso. This is an open-access article distributed under the terms of the Creative Commons Attribution License (CC BY). The use, distribution or reproduction in other forums is permitted, provided the original author(s) and the copyright owner(s) are credited and that the original publication in this journal is cited, in accordance with accepted academic practice. No use, distribution or reproduction is permitted which does not comply with these terms. 